\title{
Methodology of chemical monitoring in the marine environment*
}

\author{
W. P. Cofino \\ Ministry of Transport and Public Works, Public Works Department, Tidal Waters Division; \\ P.O. Box 20907, 2500 EX Den Haag, The Netherlands
}

\begin{abstract}
Monitoring of the marine environment requires considerable resources. Effective programs providing information tailored to needs are essential. The design of monitoring programs should follow from a clear strategy, integrating informational needs, chemical, physical and biological processes, statistics, analytical aspects and specific (chemical or hydrological) features of the area to be monitored. A quality system should be devised and maintained. In this paper, monitoring strategy is discussed and critical aspects in the execution are dealt with. Examples from the recently revised Dutch monitoring program are given.
\end{abstract}

\section{INTRODUCTION}

The contamination of the marine environment by chemical substances gives rise to considerable concern. Several signals point to possible adverse effects, the most recent being the massive blooms of Chrysochromulina polylepis along the Swedish and Norwegian coasts, and the death of seals in the North Sea observed in 1988. The problems have urged the governments of the countries along the North Sea to develop a co-operative policy for the protection of the North Sea, to which end special conferences were held in Bremen (1984) and London (1987). Special attention is devoted to the Wadden Sea, owing to the importance and ecological value of this area.

In the Ministerial Declarations a set of measures has been delineated. Along with these measures it is noted that significant improvements in monitoring data are needed for thorough assessments of the condition of the North Sea. Furthermore, national and international monitoring are considered necessary to ensure compliance with regulations to reduce inputs to the North Sea.

The need for monitoring has been expressed clearly. Several programs are operative on the national level, while internationally a program is managed by the Joint Monitoring Group of the Oslo and Paris Commissions. In addition, the International Council for Exploration of the Sea, ICES, has co-ordinated baseline studies of contaminants in fish and shellfish (ICES, 1984), and of trace metals in seawater (ICES, in preparation).

Monitoring in the marine environment has special difficulties. The levels of contaminants in samples from the marine environment are generally low and require sophisti-

* Presented at the VI International Wadden Sea Symposium (Biologische Anstalt Helgoland, Wattenmeerstation Sylt, D-2282 List, FRG, 1-4 November 1988) 
cated analytical methodology. In addition, sampling cruises are expensive, restricting in practice the extensiveness of programs. Clearly, it is of particular importance to have cost-effective programs at hand.

Evaluations of data from monitoring programs all highlight analytical problems. Inadequate detection limits, poor intercomparability, and other analytical problems are often encountered. In many cases, the analytical aspects dominate discussions to such an extent that other problems are masked.

Reliable data are a prerequisite for proper evaluations, but do not guarantee that a monitoring program will provide the information needed. To this end, the design of the whole program has to meet specifications which have to be derived from the information requirements. The quality of the information of a monitoring program depends on the quality of both design and execution.

In this paper, a framework is described for a systematic approach towards the design and implementation of (chemical) monitoring programs. The framework is based on discussions within the ICES "Marine Chemistry Working Group" and "Working Group on Environmental Assessments and Monitoring Strategies", and on experience with the monitoring program of the Dutch Public Works Department. It is stressed that quality assurance should be an integral part of the program. The latter topic will be dealt with in a more general sense, following the ISO norms 9000-9004, dealing with quality management and quality systems (ISO, 1987).

\section{THE DESIGN AND IMPLEMENTATION OF PROGRAMS FOR THE MONITORING OF CHEMICAL SUBSTANCES}

The design of monitoring programs should be rooted in clearly defined information needs, should systematically assemble relevant knowledge on characteristics of the area to be monitored, on environmental processes, statistics, and on technical aspects, and use this knowledge in an effective scheme. The implementation has to meet specified quality standards. Finally, a critical evaluation and assimilation of the data is required, employing the concepts which have been used to construct the program. The whole can be designated as the development of a monitoring strategy, and is schematically outlined in Figure 1.

Elements from this figure will be elaborated on in more detail in the following sections.

\section{Definition of information needs}

Environmental policy and management have specific requirements for information. It is of utmost importance that these requirements are described explicitly (Ward, 1986; McBride, 1986; Segar \& Stamman, 1986).

According to the objectives, a differentiation can be made between regulatory and descriptive monitoring (Harvey, 1981).

Regulatory monitoring stems from national or international legislation. For example, in the Netherlands the Public Works Department performs monitoring in the marine environment to comply with the EC directives on water for bathing (directive 76/160/EC) and on water for shellfish culture (directive $79 / 923 / \mathrm{EC}$ ). National water quality criteria have as yet not been established for marine waters, but are in preparation and will 


\section{DEFINITION OF INFORMATION NEEDS}

* qualitative and quantitative

\section{PROBLEM ANALYSIS}

* hydrography

* inputs

* environmental processes (chemical, biological and/or physical In nature)

* statistics

* analytical aspects (sampling, field measurements, analyses)

* data managment

\section{ESTABLISHMENT OF FRAMEWORK}

* compartments

* locations

* trequencles, seasons

* methodology

* data base

* quality assurance

\section{IMPLEMENTATION AND EXECUTION}

* quality control

\section{EVALUATION}

* quality assessment

* hydrography

* environmental processes

* statistics

\section{ACCOUNT OF RESULTS}

* allgnment to Information needs

Fig. 1. An outline of monitoring strategy

require monitoring too. The Agriculture Advisory Commission of the Netherlands Ministry of Agriculture and Fisheries operates a program to identify the health of fish populations, and the potential risks of fish products for consumers (Hagel, 1986). Results from this program are submitted to the Joint Monitoring Group of the Oslo and Paris Commission, to fulfill the Dutch commitments with respect to purpose "a": the assessment of possible hazards to human health.

Descriptive monitoring is a collective term for several objectives. Within the Netherlands, an important aim is to assess the effectiveness of measures taken for the reduction of marine pollution (trend monitoring), a national equivalent of purpose " $\mathrm{d}$ " of the Joint Monitoring Group. Purpose " $c$ " of the JMG, the assessment of the existing level of marine pollution, is another objective in this category. 
Often, objectives are qualitative statements. Standards are not always established or are stated rather vaguely (for example, the EC directives mentioned above). The minimum detectable trend with a significance interval is seldomly specified for trend monitoring. In order to design monitoring programs properly, and to make the word "effective" meaningful in this context, information expectations have to be defined qualitatively and quantitatively.

\section{Statistical aspects}

In a monitoring program, information has to be inferred from a series of measurements. The design of the program must have a firm statistical basis, so that the inference can be made with the desired level of significance. A discussion of available statistical techniques (e.g. time series analysis) is beyond the scope of this paper. It is stressed, however, that the application of statistical techniques should run parallel with an evaluation of the processes determining the environmental behaviour of chemical entities.

The results obtained in a certain area vary from one observation to another. The variability has spatial and temporal components and is a contribution put forward by the technical procedures employed (field measurements, sampling, analyses).

The spatial and temporal variability can partially be attributed to chemical, biological and/or physical processes affecting the concentrations in the compartment under investigation. Insight into the nature of these processes gives rise to procedures for data handling (corrections, normalisations) or sampling strategy (e.g. composite samples). In corrected or normalised datasets, the variability is usually reduced. Furthermore, the (normalised) data can be correlated internally with respect to time or other variables (e.g. salinity). Appreciation of the internal correlation structure provides a means for optimalisation of the sampling scheme and for quality assessment of the data.

The variability introduced by the technical procedures leads to several considerations.

The accuracy and precision of analytical procedures generally increase with increasing concentrations (Horwitz, 1982). In this respect, the choice of the environmental compartment for monitoring becomes important, especially for micropollutants. Variability may be reduced by analysing samples in manifold.

A leading term at this point is quality assurance within the laboratories. A facet of quality assurance is the critical selection and validation of analytical methodology, capable of performance attuned to the information needs. The laboratory also has to have the analytical procedure in statistical control, maintaining accuracy and precision at a certain level.

After consideration of relevant aspects as outlined above, the statistics will require a number of measurements to obtain the desired level of significance. Resources are limited, so that inevitably it is necessary to restrict the number of compartments and areas in order to be able to collect the required number of data.

\section{Selection of compartment}

In a schematic sense, aquatic ecosystems can be divided into the compartments biota, water, suspended solids and sediments, each of which can be subdivided further. 
The distribution of contaminants among the (sub)compartments depends on the physicochemical properties of both contaminants and compartments. In general, heavy metals and hydrophobic organic micropollutants accumulate in particulate matter and organisms. Therefore, these compartments are often preferred for monitoring, or for inventory surveys of these substances (Chapman et al., 1982; CUWVO, 1989).

The selection of compartments which accumulate (classes of) pollutants for monitoring and surveys can have several motives. It may be important to do measurements in a compartment which forms an actual or potential problem in environmental management, for example, sediments. The availability or feasibility of methods for sampling and analysis in the required concentration range are other important points to consider. This is particularly true for micropollutants, as analytical procedures (sampling, sample treatment and instrumental analysis) for measurements in seawater require specialized and cumbersome methods (e.g. Duinker \& Hillebrand, 1983; Berman \& Yeats, 1985; Mart, $1979 \mathrm{a}, \mathrm{b})$. The enhanced concentrations in accumulating compartments result in general in data with a higher level of accuracy and precision (Horwitz, 1982).

Biota and sediments give a time-averaged view of the exposure. These compartments are not appropriate for studies on processes on a short time scale. However, the time-averaging effect is an advantage, when monitoring concerns trends on longer time scales (in the order of years).

The combination of time-averaging and higher analytical accuracy and precision may result in a lower overall variability in the data, improving resolution in the trend analysis.

\section{Monitoring in sediments}

Trace metals are bound via various complexation and sorption processes (physical adsorption, chemical adsorption, ion exchange) to particulate matter. Depending on the metal and the physico-chemical conditions, precipitation also can occur (Salomons \& Förstner, 1984).

Lipophilic organic compounds have a high affinity for the organic fraction of particulate matter. The mechanism for distribution between the water and this organic phase can be represented as a partitioning process. The partitioning can be modelled with the octanol-water partitioning coefficient (Bruggeman, 1982; Davies \& Dobbs, 1984; Zaroogian et al., 1985).

Polar organic compounds generally have a high affinity for the water phase, but chemical processes may affect the distribution (e.g. chemical bounding to particulate matter).

The sorption of contaminants by particulate matter is determined by its composition, important factors being the grain size distribution and the fraction of organic material (Förstner \& Wittmann, 1979; Salomons \& Förstner, 1984; Karickhoff et al. 1979; Bruggeman, 1982). The redox conditions of the environment can severely influence the contents of trace metals in sediments and their exchange with the water phase. Factors such as resuspension and bioturbation mix the upper layer of sediments (Kramer, 1986), decreasing the attainable time resolution in trend monitoring. Furthermore, the hydrographical characteristics of the area to be studied should be taken into account: the interpretation of data extracted from sediment monitoring is different for sediment-transport, -erosion and -accumulation zones. 
In view of the influence of the composition of the sediments on the concentrations, it is necessary to apply a normalization procedure to the data before temporal or spatial comparisons can be made. Considerable attention has been paid to normalization procedures for trace metals. Possible methods include (Förstner \& Wittmann, 1979; Ackermann et al., 1983; Salomons \& Förstner, 1984):

(1) The sieving of sediments followed by measurement in the fraction with small grain size.

(2) Extrapolation of regression curves of total (trace element) content against a variable representative for the fraction of fine material.

(3) Comparison with conservative elements: the ratio between the metal and elements as $\mathrm{Al}, \mathrm{Sc}, \mathrm{Cs}$, Eu and Sm.

For organic micropollutants, measurement in the fraction with small grain size seems appropriate. A further correction for the organic carbon content may be applied.

Within the JMG it has been agreed to sieve sediments over 63 micrometer and to analyse the fine grained fraction. In cases where contamination of the coarse fraction is suspected, both fractions should be analysed.

\section{Monitoring in biota}

Biota exhibit accumulating properties for trace metals, which vary, depending on the biological species and the tissue (Martin \& Coughtrey, 1982; Phillips, 1977, 1980; Phillips \& Segar, 1986). Lipophilic organic compounds are accumulated to a high degree by fat tissues. The partitioning model described above is also applicable here.

The uptake by biota depends on the forms in which the pollutants are present in the abiotic compartments (speciation), and the physiological conditions, and the stage of development of the species. Metabolic regulation or transformation of the pollutants may occur, while interaction between pollutants may influence the uptake (Phillips \& Segar, 1986; Bryan, 1980; Bryan et al., 1980; Boon \& Duinker, 1986). Furthermore, biological factors, such as body composition, sex, age, size, sexual cycle and feeding habits, influence the concentrations of contaminants in biota (Harms \& Kerkhoff, 1988; Kruse \& Krüger, 1984; Gordon et al., 1980).

Basic prerequisites for monitoring organisms have been established: accumulation ability, high concentration factors for several contaminants, a high abundance, wide distribution, reasonable size, a sedentary mode of life, easily recognizable and collectable, availability through the whole year, and tolerance to low salinities (Phillips, 1977, 1980; Topping, 1983).

In practice, it may be difficult to find the species at all sampling stations. In some cases, the latter may be obviated by translocation of organisms (Davies \& Pirie, 1978; Simpson, 1979; de Kock, 1983).

Several types of biota have been applied, e.g. fish, shellfish, algae and plants. Mussels are frequently being used to monitor marine pollution (Goldberg et al., 1978; National Academy of Sciences, 1980; de Kock, 1986). It may be advantageous to use biota at higher trophic levels, e.g. bird eggs (Reutergårdh \& Olsson, 1986).

Variability in measurements on organisms may be decreased by selection of samples discriminating on factors such as sex, age and length. This approach has been employed in the ICES baseline study of contaminants in fish and shellfish (ICES, 1984). A further 
improvement may be attained by normalizing the concentrations to a parameter characteristic for the phase which is (estimated to be) important for the uptake. For lipophilic organic compounds such as chlorobiphenyls and polycyclic aromatic hydrocarbons, the lipid content of the tissue is an often applied parameter, concentrations being expressed on lipid basis (Boon \& Duinker, 1986; Bruggeman, 1982). Recently, it has been shown that the fat content of cod liver significantly influences the accumulation of a number of heavy metals (Grimås et al., 1985).

\section{Monitoring in the waterphase}

The water column can be considered to be composed of the compartments water and suspended particulate matter (SPM). The boundary of these two compartments is operationally defined by the separation technique employed, e.g. filtration over $0.45 \mu \mathrm{m}$ or centrifugation.

Measuring "total" water samples is not usually recommended. A large number of parameters have relatively high concentrations in the suspended particulate matter. Especially in estuaries and near coastal zones, the SPM content of samples can vary highly on small temporal and spatial scales, implying that concentrations of parameters which are strongly associated with SPM will exhibit a large variability. In open sea samples, however, filtration is often omitted owing to low SPM concentrations and the risk of contamination. Concentrations of "dissolved" chemical constituents are affected by a number of processes. An important factor is the marine water/fresh water mixing ratio. Superposed on this physical mixing of water masses, chemical and biological processes may occur. The extent of the processes can be investigated by constructing dissolved concentration-salinity plots. The salinity is a conservative parameter which can be used as an index of the mixing (Salomons \& Förstner, 1984). Substances which behave conservatively in the range studied will exhibit a linear relationship with salinity. Chemical and biological processes may lead to exchanges between phases and accordingly to deviations from the theoretical dilution line. Knowledge of the geochemical behaviour is necessary for a meaningful interpretation of the results.

As an example, salinity plots are given in Figure 2. In Figure $2 \mathrm{~A}$, the dissolved $\mathrm{Cd}$ salinity plot is given for the Western Scheldt, with data obtained in 1979 and 1986 by Yeats, Berman, Willie, Myktivk and Cofino (unpubl.). The profile is characteristic for estuarine addition. A comparison of the profiles measured in 1979 and 1986 indicates that the Cd burden has been reduced. This finding is confirmed by monitoring with mussels. Conservative behavior has been observed for dissolved $\mathrm{Cu}$ for the Dutch coast (Fig. $2 \mathrm{~B}$ ). The river Rhine provides the principal component in the freshwater fraction. In principle, changes in the copper emissions will become visible by changes in the angle of inclination, providing corrections are made for differences in the river discharge. The data indicate that the copper emissions were quite stable in the period between 1983 and 1987.

Conservative behavior has also been found for the Dutch coast for dissolved Ni, Zn, $\mathrm{Pb}$ and, in the winter season, for nutrients.

Monitoring in suspended particulate matter has not been carried out on a large scale up to now, presumably due mainly to problems with collecting a sufficient amount of material for analysis. SPM is an important compartment because similar to sediments it is 

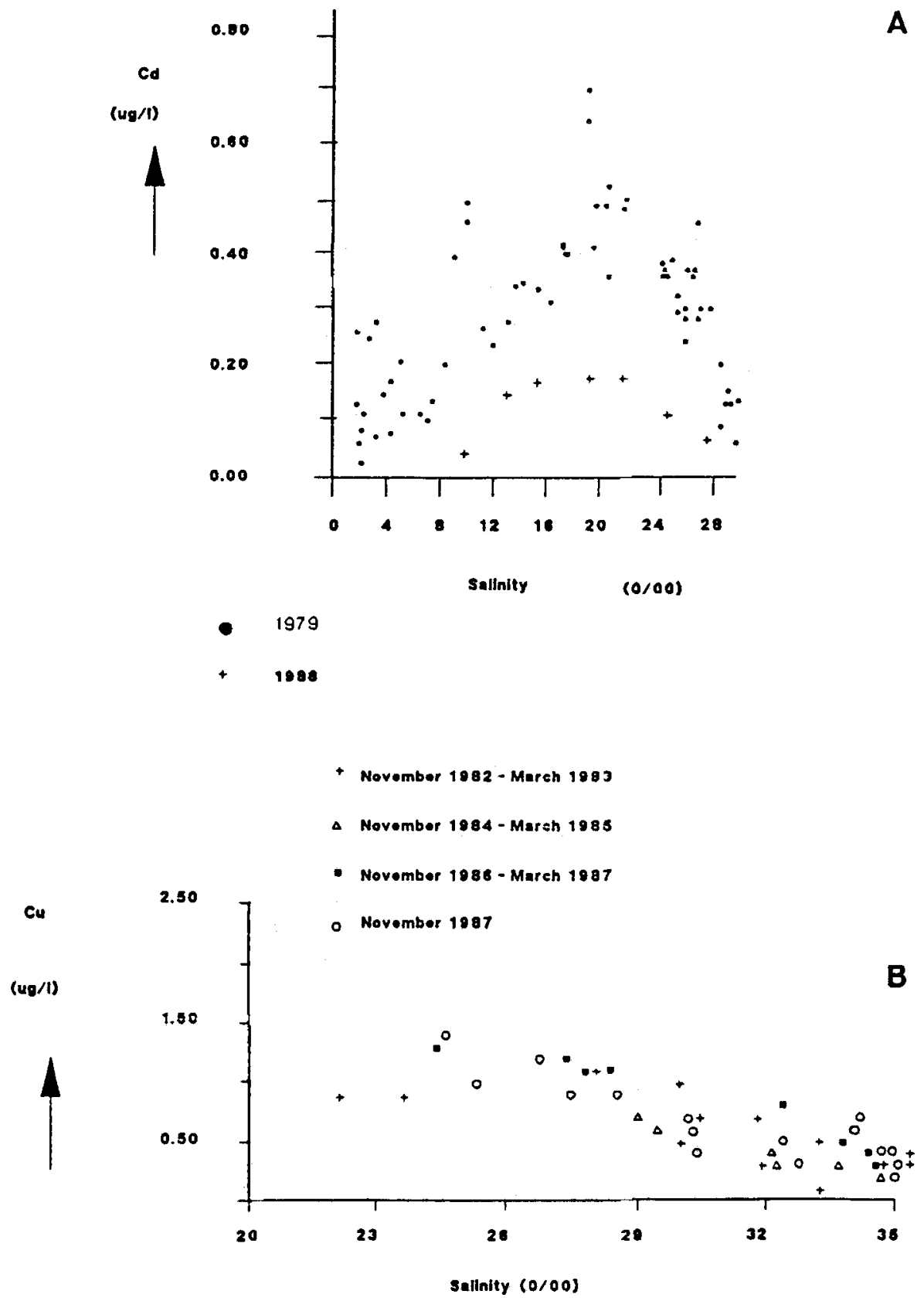

Fig. 2. Dissolved metal-salinity plots. A: Cadmium in the Western Scheldt in 1979 (Kerdijk \& Salomons, 1981) and 1986 (Yeats, Berman, Willie, Myktivk and Cofino, unpublished results). B: Copper at stations along the Dutch coast. For every year, data from November to March have been summed 
enriched, in contrast to water, with heavy metals and hydrophobic organic micropollutants, and as carrier it determines to a significant extent the pathway of (classes of) pollutants through the marine environment.

The collection of SPM in estuaries and near coastal zones can be carried out conveniently with continuous flow centrifuges. The composition of SPM may depend on the season and on the hydrological and meteorological conditions. As with sediments, corrections for the composition are necessary. Despite these problems, SPM is a suitable compartment for monitoring or surveys (Chapman et al., 1982; CUWVO, 1989).

\section{The density of stations and frequency of sampling}

Preferably, the selection of sampling areas is based on investigations, revealing basic information on hydrology and the environmental behavior of the substances to be monitored.

The station density and frequency of sampling should be derived from a statistical evaluation, accounting for temporal and spatial correlations and the variability adherent to the measurements. In general, in estuaries and coastal zones a number of stations along salinity and/or pollution gradient will be chosen. The coherence between the data of different stations provides a basis for quality assessement and interpretation. In areas with a more homogeneous water mass (open sea), several samples in an area will be required.

\section{QUALITY MANAGEMENT OF DATA AND INFORMATION}

Recently, the International Organisation for Standardisation (ISO) has released a series of standards (9000-9004) dealing with quality management and quality systems (ISO, 1987).

The standards provide guidelines to manage organisations in such a manner that quality objectives are met. Important are

- the organisation has to formulate a quality policy, describing quality objectives and the means and resources to achieve them. This policy has to be confirmed by the managing board.

- In compliance with above, quality management is necessary, implying strategic planning, the allocation of facilities and resources and the presence of a quality system.

The quality system encompasses the technical, administrative and human factors which affect the quality in all phases from the assessment of quality requirements to the product.

For laboratories working in the pharmaceutical or toxicological field, requirements for the quality system, commonly known as Good Laboratory Practice (GLP), are often posed by national regulatory agencies. No comparable national or international requirements exist for laboratories working in the environmental field. The GLP principles may be adapted for use by these laboratories. In the Netherlands, the Dutch Standards Organisation has published a general standard (NEN 2653) for Quality Assurance in laboratories. The Joint European Standards Institution, CEN/ CENELEC, has a standard with a comparable scope, EN 45001, in preparation.

The principles of quality management apply to both laboratories and to the national 
and international bodies managing monitoring programs. These two levels will be discussed separately.

\section{Quality management in laboratories}

The quality system provides laboratories a framework to provide valid data. Elements of this program are the proper elaboration and documentation of

(1) the "infra-structure" of the laboratory: allocation of responsibilities, level of education, facilities, safety rules, administrative procedures and so on

(2) treatment and maintenance of facilities, equipment (including calibration-, optimizing-, operation-procedures)

(3) all analytical procedures

(4) a quality assessment program.

Guidelines for the construction of a quality system can be found in literature (e.g. Vijverberg \& Cofino, 1987). It is stressed, however, that a quality system is an aid, and not a guarantee, for obtaining qualitatively sound data. A critical judgement by professional, motivated analytical chemists is required at all steps.

Special attention has to be paid to the validation of analytical methodology and quality assessment measures.

The selection and the development of analytical methodology has to be directed by requirements derived from the objective of the measurements. After development, validation is needed (Taylor, 1983). Firstly, it must be assessed that the measuring process is in statistical control. This will involve a series of measurements rendering information on the precision. Secondly, the accuracy should be established. This can be accomplished by measuring certified reference materials, and/or by comparing with a method or laboratory with known accuracy. The analytical methods ought to be validated before application.

Laboratories need to take measures to ensure that they maintain a certain level of accuracy and precision. Control charts are important tools for internal quality assessment. These charts are graphical means for monitoring the measurement process or the status of an instrument, and provide feedback for process control (ASTM 1976; Juran et al., 1974; Kateman \& Pijpers, 1981; Vijverberg \& Cofino, 1987; National Institute of Standards and Technology, 1985; Ishikawa, 1982). Quality parameters like reference materials, measurements of blanks or standard solutions, the difference between duplicate measurements, sensitivity and so on can be recorded. Notably the use of certified or selfmade reference materials combined with control charts is a powerful tool for internal quality assessment.

Sampling and working up of samples are critical points, specifically for trace metals and organics. A well ordered laboratory and stimulating (quality) management should create the conditions for handling these problems adequately.

\section{Quality management in the organization managing the monitoring program}

The organization managing the program should develop a quality system. In a manual, an outline of the monitoring program and all administrative and technical procedures should be documented. 
Special attention has to be devoted to the quality assurance of the data submitted by the participating laboratories.

Standardization of all methods for sampling and analysis is recommended but not always possible. A scheme for quality assurance of data is:

(1) specification of the analytical methodology as far as feasible;

(2) prescription of the procedure for validation of analytical methodology, assessing both statistical control and accuracy with the aid of, for example, certified reference materials (see also ICES, 1989);

(3) the implementation of a quality assessment program.

The managing organization could disseminate uncertified reference materials. Participating laboratories should analyse these materials regularly in the same runs as the actual samples. Data on both the "external reference material" and the samples should be reported. This approach resembles a long-term intercalibration and makes it possible to reveal systematic differences or lack of control.

\section{AN OUTLINE OF THE MONITORING PROGRAM OF THE DUTCH PUBLIC WORKS DEPARTMENT}

The program was revised in 1988. Details on the previous program have been described by Beukema et al. (1986).

Regulatory ("control") monitoring is performed to comply with the EC directives 76/ 160/EC and 79/923/EC (see section 2.1). In addition, specific parameters are determined at "hot spot" areas.

Monitoring to establish the effectiveness of measures to reduce pollution is performed in several environmental compartments as summarized in the following table (Table 1):

Table 1. Environmental compartments monitored to establish effectiveness of measures to reduce pollution

\begin{tabular}{|lcccc|}
\hline Parameter & Water & $\begin{array}{c}\text { Compartment } \\
\text { Suspended } \\
\text { particulate matter }\end{array}$ & Sediment & Mytilus edilus \\
\hline Nutrients & $\mathbf{x}$ & $\mathbf{x}$ & $\mathbf{x}$ & $\mathbf{x}$ \\
Trace metals & $\mathbf{x}$ & $\mathbf{x}$ & $\mathbf{x}$ & $\mathbf{x}$ \\
PCBs, PAHs & & & \\
\hline
\end{tabular}

The suspended particulate matter is collected with continuous flow centrifuges. Mytilus edilus are collected in the Eastern Scheldt and selected according to length. Three times a year, baskets with approximately a hundred individuals are translocated to fifteen stations. After six weeks, the baskets are collected and the samples are analysed.

In addition, in every compartment parameters are measured in order to characterize the matrix.

This scheme is considered a good balance between monitoring in different compartments and restricted resources. 


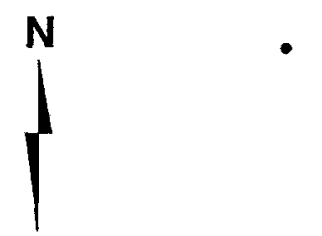

- watersamples

- musselwatch, at 8 stations in addition contaminants In suspended solids

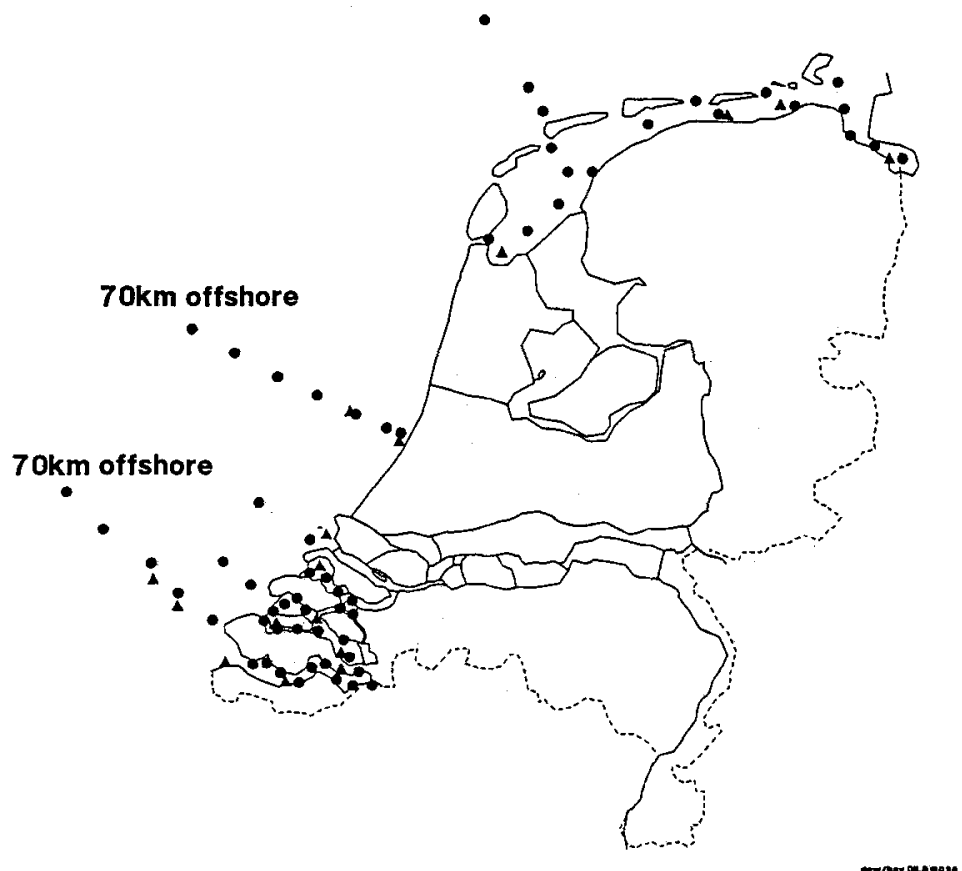

Fig. 3. Map indicating the sampling stations

Frequencies and locations have been chosen on the basis of data available from monitoring and projects. An overview is given in Figure 3.

\section{LITERATURE CITED}

Ackermann, F., Bergmann, H. \& Schleichert, W., 1983. Monitoring of heavy metals in coastal and estuarine sediments. A question of grain size: $<20 \mathrm{mu}$ versus $<60 \mathrm{mu}$. - Environ. Technol. Lett. 4, $317-328$.

ASTM Committee E-11, 1976. ASTM Manual on presentation of data and control chart analysis, $S T P-15 D$.

Berman, S. S. \& Yeats, P. A., 1985. Sampling of seawater for trace metals. - CRC crit. Rev. analyt. Chem. 16, 1-14. 
Beukema, A. A., Hekstra, G. P. \& Venema, C., 1986. The Netherlands' environmental policy for the North Sea and Wadden Sea. - Environ. Monit. Assess. 7, 117-156.

Boon, J. P. \& Duinker, J. C., 1986. Monitoring of cyclic organochlorines in the marine environment. Environ. Monit. Assess. 7, 189-208.

Bruggeman, W. A., 1982. Hydrophobic interactions in the aquatic environment. In: Handbook of environmental chemistry. Ed. by O. Hutzinger. Springer, Berlin, 2B, 83-102.

Bryan, G. W., 1980. Recent trends in research on heavy-metal contamination in the sea. - Helgoländer Meeresunters. 33, 6-25.

Bryan, G. W., Langston, W. J. \& Hummerstone, L. G., 1980. The use of biological indicators of heavy metal contamination in estuaries. - Occ. Publ. mar. biol. Ass. U.K. 1, 1-73.

Chapman, P. M., Patrick Romberg, G. \& Vigers, G. A., 1982. Design of monitoring studies for priority pollutants. - J, Wat. Pollut. Control Fed. 54, 292-297.

CUWVO (Coordinatiecommissie Uitvoering Wet Verontreiniging Oppervlaktewateren), 1989. Aanbevelingen voor het onderzoek naar microverontreinigingen in aquatisch milieu. Public Works Dept., The Hague, $84 \mathrm{pp}$.

Davies, I. M. \& Pirie, J. M., 1978. The mussel Mytilus edilus as a bioassay organism for mercury in seawater. - Mar. Pollut. Bull. 9, 128-132.

Davies, R. P. \& Dobbs, A. J., 1984. The prediction of bioconcentration in fish. - Wat. Res. 18, 1253-1262.

Duinker, J. C. \& Hillebrand, M. T. J., 1983. Determination of selected organochlorines in seawater. In: Methods of seawater analyses. Ed. by K. Grasshoff, M. Ehrhardt \& K. Kremling. Verl. Chemie, Weinheim, 290-309.

Förstner, U. \& Wittmann, G., 1979. Metal pollution in the aquatic environment. Springer, Berlin, $486 \mathrm{pp}$.

Goldberg, E. D., Bowen, V. T., Farrington, J. W., Harvey, G., Martin, J. H., Parker, P. L., Risebrough, R. W., Robertson, W., Schneider, E. \& Gamble, E., 1978. The Mussel Watch. - Environ. Conserv. 5, 101-125.

Gordon, M., Knauer, G. A. \& Martin, J. H., 1980. Mytilus californianus as a bioindicator of trace metal pollution: variability and statistical considerations. - Mar. Pollut. Bull. 11, 195-198.

Grimås, U., Gothberg, A., Notter, M., Olsson, M. \& Reutergårdh, L., 1985. Fat amount - a factor to consider in monitoring studies of heavy metals in cod liver. - Ambio 14, 175-178.

Hagel, P., 1986. Monitoring of pollutants in Dutch fishery products. - Environ. Monit. Assess. 7, $257-262$.

Harms, U. \& Kerkhoff, M. A. T., 1988. Accumulation of pollutants by fish. In: Pollution of the North Sea. Ed. by W. Salomons, B. Bayne, E. Duursma \& U. Förstner. Springer, Berlin, 687 pp.

Harvey, T., 1981. Environmental intervention: the monitoring paradigm. I. - Environmentalist 1 , $283-291$.

Horwitz, H., 1982. Evaluation of analytical methods used for regulation of foods and drugs. - Analyt. Chem. 54, 67A-75A.

ICES, 1984. The ICES coordinated monitoring programme for contaminants in fish and shellfish, 1978 and 1979 and six year review of ICES coordinated monitoring programmes. - Coop. Res. Rep. 126, 1-100.

ICES, 1989. Report of the meeting of the Marine Chemistry Working Group. ICES, Copenhagen, 42 pp.

Ishikawa, K., 1982. Guide to quality control. Asian Productivity Organization, Tokyo, $226 \mathrm{pp}$.

ISO, 1987. Quality management and quality assurance standards. - Guidelines for selection and use. (ISO standard 9000.)

ISO, 1987. Quality systems. Model for quality assurance in design/development, production, installation and servicing. (ISO standard 9001.)

ISO, 1987. Quality systems. Model for quality assurance in production and installation. (ISO standard 9002.)

ISO, 1987. Quality systems. Model for quality assurance in final inspection and test. (ISO standard 9003.)

ISO, 1987. Quality management and quality system elements. Guidelines (ISO standard 9004.)

Juran, J. M., Seder, L. A. \& Gryna, F. M., 1974. Quality control handbook. McGraw-Hill, New York, getr. Pag. 
Kateman, G. \& Pijpers, F. W., 1981. Quality control in analytical chemistry. Wiley, New York.

Karickhoff, S. W., Brown, D. S. \& Scott, T. A., 1979. - Wat. Res. 13, 241.

Kerdijk, H. N. \& Salomons, W., 1981. Heavy metal cycling in the Scheldt Estuary. - Delft Hydraulics Rep. M1640/M1736.

Kock, W. C. de, 1983. Accumulation of cadmium and polychlorinated biphenyls by Mytilus edilus transplanted from pristine water into pollution gradients. - Can. J. Fish. aquat. Sci. 40, 282-294.

Kock, W. C. de, 1986. Monitoring bio-available marine contaminants with mussels (Mytilus edilus L.) in the Netherlands. - Environ. Monit. Assess, 7, 209-220.

Kramer, C. J. M., 1986. Monitoring of abiotic compartments for trace metals: Difficulties, strategies and the use of surveys. - Environ. Monit. Assess. 7, 169-187.

Kruse, R. \& Krüger, K., 1984. Untersuchungen von Nordseefischen auf Gehalte an toxischen Schwermetallen und chlorierten Kohlenwasserstoffen im Hinblick auf lebensmittelrechtliche Bestimmungen. - Arch. Lebensmittelhyg. 35, 128-131.

Mart, L., 1979a. Prevention of contamination and other accuracy risks in voltammetric trace metal analysis of natural waters. Part I. Preparatory steps, filtration and storage of water samples. Fresenius Z. analyt. Chem. 296, 250-257.

Mart, L., 1979b. Prevention of contamination and other accuracy risks in voltammetric trace metal analysis of natural waters. Part II. Collection of surface water samples. - Fresenius Z. analyt. Chem. 299, 97-102.

Martin, M. H. \& Coughtrey, P. J., 1982. Biological monitoring of heavy metal pollution. Applied Science Publ., London, 475 pp.

McBride, G. B., 1986. Requirements of a water quality information system for New Zealand. - IAHS Publ. 157, 29-35.

National Academy of Sciences, 1980. The international mussel watch. National Academy of Sciences, Washington D.C., $284 \mathrm{pp}$.

National Institute of Standards and Technology, 1985. Standard reference materials, handbook for SRM users. - Spec. Publ, natn. Inst. Stand. Tech. 260-100, 98 pp.

Phillips, D. H. J., 1977. The use of biological indicator organisms to monitor trace metal pollution in marine and estuarine environments - a review. - Environ. Pollut. 13, 281-317.

Phillips, D. J. H., 1980. Quantitative aquatic biological indicators. Applied Science Publ., London, $488 \mathrm{pp}$.

Phillips, D. J. H. \& Segar, D. A., 1986. Use of bio-indicators in monitoring conservative contaminants: Programme design imperatives. - Mar. Pollut. Bull. 17, 10-17.

Reutergårdh, L. \& Olsson, M., 1986. Marine monitoring of organochlorine compounds, selection of media in relation to trends and detection levels. - ICES Marine Chemistry Working Group Meet. Doc. $7.2 .5 / 1$

Salomons, W. \& Förstner, U., 1984. Metals in the hydrocycle. Springer, Berlin, 349 pp.

Segar, D. A. \& Stamman, E., 1986. Fundamentals of marine pollution programme design. - Mar. Pollut. Bull. 17, 194-200.

Simpson, R. D., 1979. Uptake and loss of zinc and lead by mussels (Mytilus edilus) and relationships with body weight and reproductive cycle. - Mar. Pollut. Bull. 10, 74-78.

Taylor, J. K., 1983. Validation of analytical methods. - Analyt. Chem. 55, 600A-608A.

Topping, G., 1983. Guidelines for the use of biological material in first order pollution assessment and trend monitoring. - Scott. Fish. Res. Rep. 28, 1-28.

Vijverberg, F. A. J. M. \& Cofino, W. P., 1987. Control procedures: good laboratory practice and quality assurance. - ICES Tech. mar. environ. Sci. 6, 1-33.

Ward, R. C., 1986. Framework for designing water quality information systems, - IAHS Publ. 157, 89-98.

Zaroogian, G. E., Heltshe, J. F. \& Johnson, M., 1985. Estimation of bioconcentration in marine species using structure-activity models. - Environ. Toxic. Chem. 4, 3-12. 